\title{
The Effect of Niobium and Rubidium Doping on the Energy Band Gap of a Lithium Tantalate $\left(\mathrm{LiTaO}_{3}\right)$ Thin Film
}

\author{
Agus Ismangil $^{1 *}$, Fatimah Arofiati Noor ${ }^{1}$, Toto Winata ${ }^{1}$ \\ ${ }^{1}$ Departement Physics, Faculty of Mathematics and Natural Science, Institut Technologi Bandung, Jalan Ganesa no. 10 \\ Bandung, Indonesia
}

( Received: December 8, 2021, Revised: December 23, 2021, Accepted: December 29, 2021 )

\begin{abstract}
Chemical solution deposition (CSD) is a technique for making a film by keeping synthetic arrangements on the outer layer of the substrate. The outcomes show that the band gap energy of the $\mathrm{LiTaO}_{3}$ film is $1 \mathrm{eV}$. Electrons are more effectively invigorated to the valence band than to the conduction band on the grounds that the energy required is not excessively huge. Niobium-doped $\mathrm{LiTaO}_{3}$ film has a band gap energy of $1.15 \mathrm{eV}$. A large amount of energy is needed for electrons to be energized from the valence band to the conduction band. The rubidium-doped $\mathrm{LiTaO}_{3}$ film has a band gap energy of $1.30 \mathrm{eV}$.
\end{abstract}

Keywords: band gap energy, lithium tantalate, niobium, rubidium.

\section{INTRODUCTION}

A semiconductor is a material with an electrical conductivity that is between that of an insulator and a conductor [1]-[4]. Semiconductors are very useful in electronics because their electrical conductivity can be changed by injecting them with another material, a technique commonly known as doping. Semiconductors are basic elements of electronic components such as diodes, transistors, and integrated circuits (ICs) [5],[6]. Semiconductors are very widely used, especially since the invention of the transistor in the late 1940s [7]-[10]. The most well-known semiconductor materials are silicon $(\mathrm{Si})$, germanium (Ge), and gallium arsenide (GaAs) [11][13]. Semiconductors that have been doped by atoms with different band structures and electrical resistivities will experience property changes [14],[15]. Impurities in semiconductors can donate electrons and gaps in the energy band. The electron concentration cannot be the same as the hole concentration; however, each depends on the concentration and the type of impurity material. Sometimes, only materials with electron charge carriers or holes are required [16]. This is done by injecting impurities into the semiconductor [17].

To obtain high-quality semiconductor devices, the "purity" and "single crystal perfection" of the semiconductor must be considered [18]. This is because, in general, the addition of a small number of impurities affects the charge carrier, thus affecting the components being made [19]. On the other hand, the more perfect the crystal, the less damage to the crystal layer. The perfection of this crystal greatly determines the characteristics of the components it is made of [20],[21]. Intrinsic semiconductors are semiconductors that consist of only one element, such as Si or Ge only [22],[23]. In Si semiconductor crystals, $1 \mathrm{Si}$ atom, which has 4 valence electrons, is bonded to 4 other $\mathrm{Si}$ atoms. In the intrinsic semiconductor crystal $\mathrm{Si}$, the primitive cell is cuboid. The bond that occurs between adjacent $\mathrm{Si}$ atoms is a covalent bond. This is due to the sharing of 1 electron by two adjacent $\mathrm{Si}$ atoms [24]. According to the energy band theory, at $T=0 \mathrm{~K}$, the valence band of a semiconductor is filled with electrons, while the conduction band is empty. The two bands are separated by a small energy gap, which is in the range

\footnotetext{
* Corresponding author.

E-mail address: a.ismangil.physics@gmail.com
} 
of $0.18 \mathrm{eV}$ to $3.7 \mathrm{eV}$. At room temperature, $\mathrm{Si}$ and $\mathrm{Ge}$ have energy gaps of $1.11 \mathrm{eV}$ and $0.66 \mathrm{eV}$ [25].

The role of $\mathrm{LiTaO}_{3}$ ferroelectric material is interesting to study because of its use in infrared sensors [26]. $\mathrm{LiTaO}_{3}$ is an object that has been intensively studied in recent years due to its unique properties. $\mathrm{LiTaO}_{3}$ is ferroelectric at room temperature. From several studies, it has been determined that $\mathrm{LiTaO}_{3}$ is an optical, pyroelectric, and piezoelectric material. $\mathrm{LiTaO}_{3}$ has a high dielectric constant and a high charge storage capacity, as well [27]. In addition, $\mathrm{LiTaO}_{3}$ is a nonhygroscopic crystal that is not easily damaged by its optical properties. This property makes $\mathrm{LiTaO}_{3}$ superior to other materials [28]-[30].

The purpose of this study is to determine the band gap energy value of pure lithium tantalate $\left(\mathrm{LiTaO}_{3}\right)$ film doped with niobium and rubidium, which was characterized by reflectance.

\section{EXPERIMENTAL METHOD}

The materials used in this research are Lithium Acetate [LiO2C2H3] powder, Tantalum Oxide [Ta2O5] powder, 2-methoxyethanol [C3H8O2], Niobium [NiO3], Rubidium [RuO2] powder, p-type $\mathrm{Si}$ (100) substrate, deionized water, acetone PA [CH3COCH3, $58.06 \mathrm{~g} / \mathrm{mol}$ ], methanol PA [CH3OH, $32.04 \mathrm{~g} / \mathrm{mol}$ ], fluoride acid (HF), glass preparations, silver paste, fine copper wire, and aluminum foil. In this experiment, $\mathrm{LiTaO}_{3}$ thin film was made using the chemical solution deposition (CSD) method, a technique for making films by saving synthetic arrangements on the outer layer of the substrate. The tempering system is completed in stages using the Heater Vulcan TM 3-130. The motivation behind tempering is to diffuse the $\mathrm{LiTaO}_{3}$ arrangement with a silicon substrate, beginning at room temperature and raised to a tempering temperature of $800^{\circ} \mathrm{C}$. In Figure 1 temperature increases of $1.7^{\circ} \mathrm{C} / \mathrm{min}$ is used, and the temperature is held steady for 8 hours at the strengthening temperature. Further cooling is done until room temperature is reached.

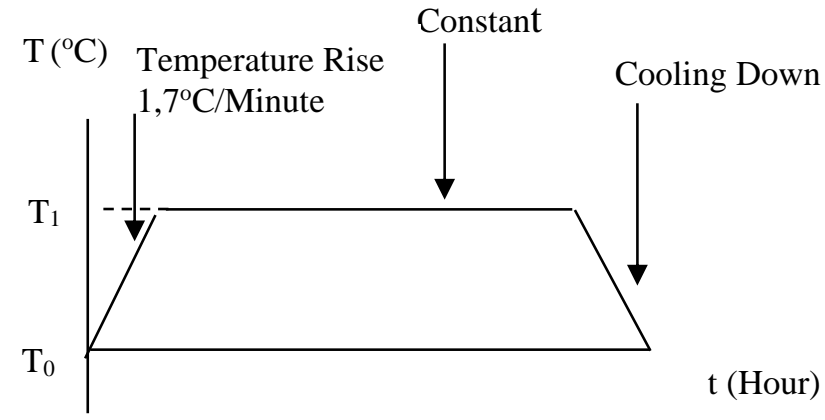

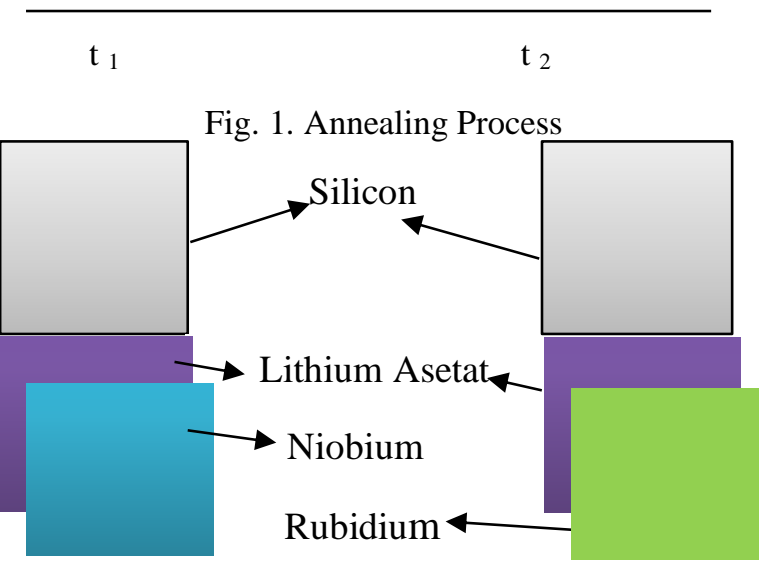

Fig. 2. $\mathrm{LiTaO}_{3}$ Thin Film Design

In the exploration stage, the most common way of developing thin films involves utilizing the CSD strategy on the reactor surface twist coaters. In Figure 2 cleaned silicone substrate is set on the outer layer of the twist coater reactor plate, then one-third of the substrate is shut using covering tape. The next third of the substrate is trickled with $\mathrm{LiTaO}_{3}$ arrangement with as much as one drop and three redundancies. The twist reactor coater is set at $3000 \mathrm{rpm}$ for 30 seconds for each drop of $\mathrm{LiTaO}_{3}$ arrangement. Next the tempering system is used to diffuse the $\mathrm{LiTaO}_{3}$ arrangement with a silicon substrate, forming a thin layer. The tempering process uses the heater Vulcan TM 3-130, with a temperature ascent of $1.7^{\circ} \mathrm{C} / \mathrm{min}$ from room temperature to the ideal temperature wanted at different temperatures. A thin film of lithium tantalate $\left(\mathrm{LiTaO}_{3}\right)$ is created, and the optical properties are observed using a spectrophotometer.

Testing optical properties in the form of reflectance values was carried out to observe the spectrum of light reflection from the $\mathrm{LiTaO}_{3}$ thin film. The light source used is visible light and the tool used is the UV-Vis Ocean Optics USB4000 Spectroscopy. The analysis of the reflectance value is done by calculating the energy gap value.

The energy gap is obtained by plotting the relationship between (1) and (2), given below:

$\alpha h v=A\left(h v-E_{g}\right)^{n}$

$h v=\left[\ln \frac{\left(R_{\max }-R_{\min }\right)}{\left(R-R_{\min }\right)}\right]^{2}$

Description: $\alpha$ is the absorbance coefficient $\left(\mathrm{cm}^{\wedge}-1\right)$, $h$ is Planck's constant $(4.135669 \times 10-15 \mathrm{eV} \cdot \mathrm{s}), v$ is the light frequency $(\mathrm{Hz}), E_{g}$ is the band gap energy 
$(\mathrm{eV}), R$ is the reflectance value (\%), and $\mathrm{d}$ is the film thickness $(\mathrm{cm})$.

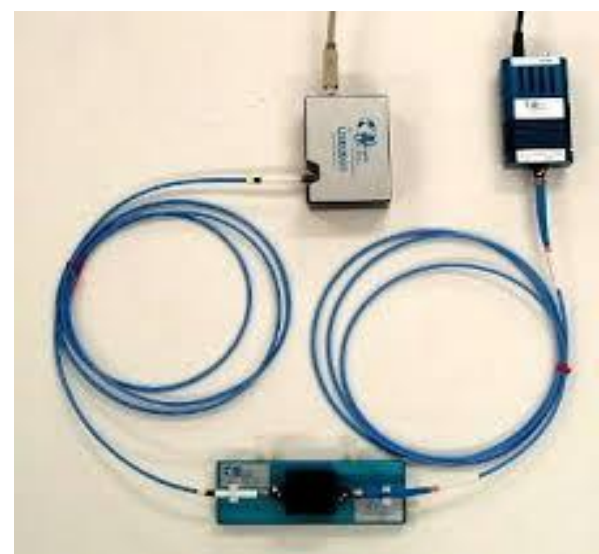

Fig. 3. Ocean optic tools [31]

The spectrophotometry is an insightful technique dependent on the absorption of electromagnetic radiation. As seen in Figure 3 absorption spectroscopy has five main components, namely a radiation source, monochromator, sample, detector, and recorder. The radiation source used is a xenon lamp which is commonly used in spectroscopy, while the monochromator functions to produce a beam of radiation with one wavelength. Light comprises of radiation that has varying levels of affectability to the human eye; various frequencies will create distinctive light while a combination of light with frequencies will make up white light. White light covers the spectrum of wavelengths ranging from 400 to $980 \mathrm{~nm}$. A spectrophotometer is made from a radiation source, a monochromator, and permeable cells of the camped arrangement. This spectrophotometer possibly happens when electrons move from a lower energy level to a higher energy level. When the exchange of electrons isn't joined by a shift during twist, this is known as energized singlet.

\section{RESULTS AND DISCUSSION}

An ingestion spectrophotometer has five fundamental parts: the radiation source, the monochromator, the test, the indicator, and the recorder. The radiation source utilized is xenon light, which is a typical source for spectrophotometers. In the monochromator, a radiation pillar with one frequency is transmitted through the output slit. Radiation with a specific frequency will be retained and other radiation will be communicated or reflected. The spectrophotometer is a useful instrument dependent on the retention of electromagnetic radiation.
The energy gap is a base amount of energy that an electron needs to move from the valence band to the conduction band. The electrons in this valence band can move to the conduction band with the expansion of outer energy, which can come from an outside electric field, nuclear power, and photon energy. Estimation of the optical properties of thin films utilizes frequencies in the range of $400 \mathrm{~nm}$ to $980 \mathrm{~nm}$. The frequency range incorporates bright, visible, and infrared light.

The assurance of the energy gap is done utilizing the Tauc plots technique. Assurance of the value of the energy gap ascertains the energy gap esteem, $(\ln (R$ $\left.\left.{ }_{\max }-R_{\min }\right) /\left(R_{\max }-R_{\min }\right)\right)$ with $\mathrm{h}(\mathrm{c} / \lambda)$ plotted, then, at that point, a straight boundary is defined through the foci encountered by adjusting the upward boundary of the extraordinarily enormous in Figure 4. The convergence of the lines with the even pivot shows the value of the energy gap. The large gap doped energies of niobium and rubidium just as unadulterated $\mathrm{LiTaO}_{3}$ thin films are displayed in Figure 4, as well. The energy gap is determined using the Tauc plot strategy.

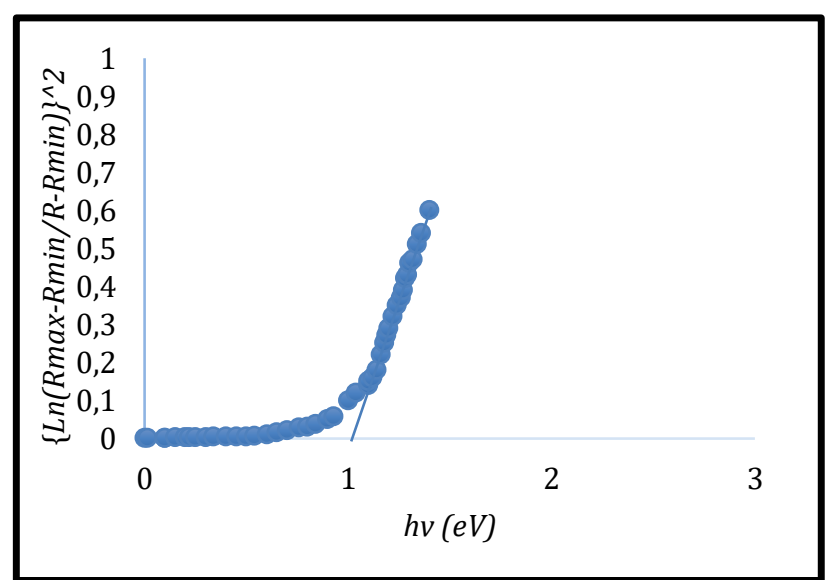

(a)

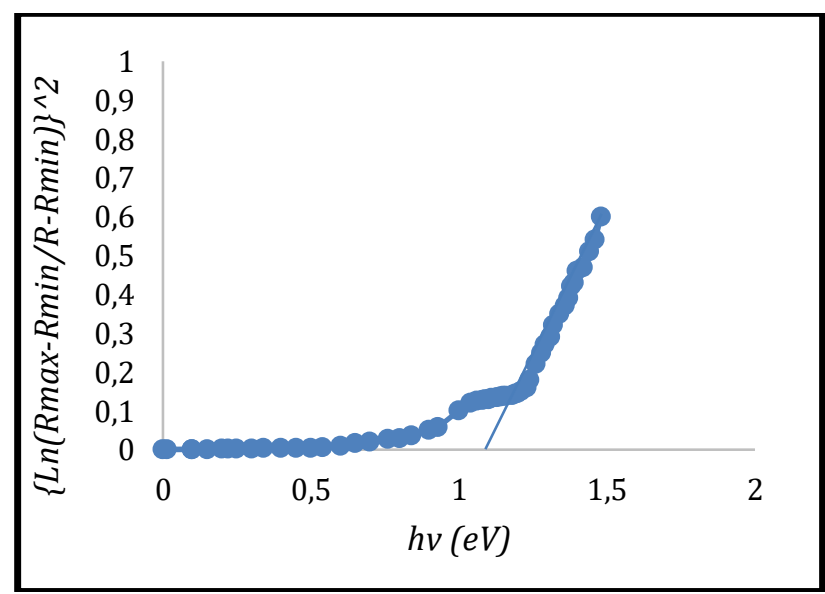

(b) 


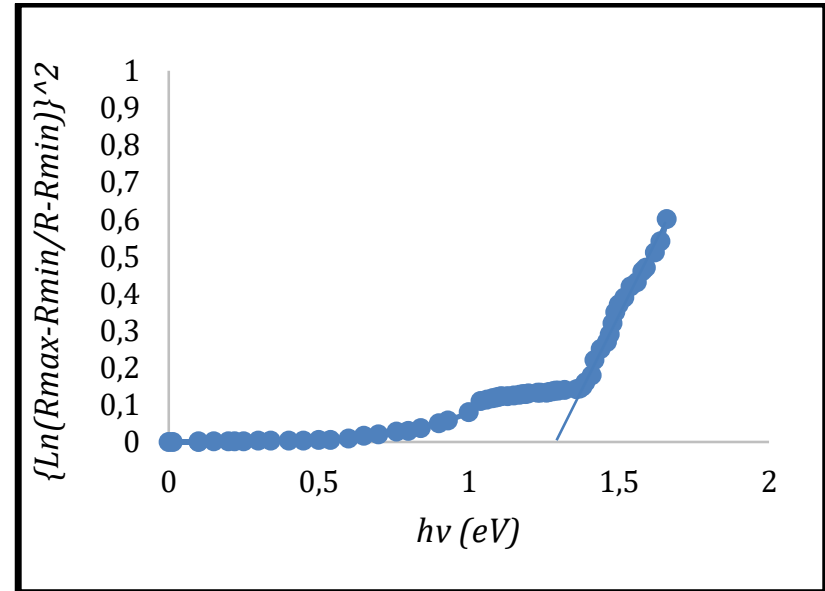

(c)

Fig. 4. Band gap energy of (a) pure $\mathrm{LiTaO}_{3}$ (b)Niobium doped (c) Rubidium doped seen in the graph shows the band gap energy in pure $\mathrm{LiTaO}_{3}$ and doped with Niobium, the band gap energy shifts, as does Rubidium doped.

Figure 4 shows the value of the reflectance of the thin film produced using $\mathrm{LiTaO}_{3}$ without doping, has a band gap energy of $1 \mathrm{eV}$. When a thin film made of $\mathrm{LiTaO}_{3}$ was doped with niobium, it created a band gap energy of $1.15 \mathrm{eV}$. When a thin film made of $\mathrm{LiTaO}_{3}$ was doped with rubidium, it created a band gap energy of $1.30 \mathrm{eV} . \mathrm{LiTaO}_{3}$ thin films, when doped with niobium and rubidium, shows an increased the band gap energy. This shows that the electrons in the niobium and rubidium doped $\mathrm{LiTaO}_{3}$ thin films will diminish, compared to the unaltered $\mathrm{LiTaO}_{3}$ thin films. This is significant because the thin film of $\mathrm{LiTaO}_{3}$ will generally retain photons with the least energy excitation. It is hypothetically conceivable that both the unaltered and niobium and rubidium doped $\mathrm{LiTaO}_{3}$ thin films on semiconductor materials are dependent on the value of the energy gap going from $1 \mathrm{eV}$ to $3 \mathrm{eV}$, and this can be utilized in the form of dynamic healing for electronic gadgets.

\section{CONCLUSION}

The results show that the band gap energy of a pure $\mathrm{LiTaO}_{3}$ film $1 \mathrm{eV}$. Electrons are more easily excited to the valence band than to the conduction band because the energy required is not too large and the Niobium-doped $\mathrm{LiTaO}_{3}$ film has a band gap energy of $1.15 \mathrm{eV}$. A large amount of energy is required for electrons to get excited from the valence band to the conduction band. Meanwhile, the rubidium doped $\mathrm{LiTaO}_{3}$ film has a band gap energy of $1.30 \mathrm{eV}$.

\section{REFERENCES}

[1] Irzaman et al., Application of lithium tantalate $\left(\mathrm{LiTaO}_{3}\right)$ films as light sensor to monitor the light status in the Arduino Uno based energy-saving automatic light prototype and passive infrared sensor, Ferroelectrics, 524, 44-55, 2018,

[2] Irzaman et al., Characterization of Lithium Tantalate $\left(\mathrm{LiTaO}_{3}\right)$ Film on the Concentration Variations of Ruthenium Oxide ( $\mathrm{RuO} 2)$ Dope, Integrated Ferroelectrics, 201, 32-42, 2019,

[3] A. Ismangil, and H. P. Susanto, Design of power bank mobile using solar panel based microcontroller atmega 328 - IOPscience, 621, 012008, 2019.

[4]A.Ismangil, Irzaman, and Irmansyah, Development of Lithium Tantallite $\left(\mathrm{LiTaO}_{3}\right)$ for Automatic Switch on LAPAN-IPB Satellite Infra-red Sensor, Elsevier Enhanced Reader, 1, 1-6, 2014.

[5] P. K. Joshi et al., Electronic properties of lithium tantalate using Compton spectroscopy, J. Phys, Conf. Ser, 1504, 012015, 2020.

[6] W. He et al., First-principles investigation of vacancies in LiTaO3, J. Phys, Condens. Matter, 28, 315501, 2016.

[7] Irzaman et al., Formation of solar cells based on Ba0.5Sr0.5TiO3 (BST) ferroelectric thick film, AIP Conference Proceedings, 1586, 24-34, 2014.

[8] K. Edalati et al., Improved Photocatalytic Hydrogen Evolution on Tantalate Perovskites $\mathrm{CsTaO}_{3}$ and $\mathrm{LiTaO}_{3}$ by Strain-Induced Vacancies, ACS Applied Energy Materials, 3, 1710-1718, 2020. [9] B. Sun, et al., Influence of thermal annealing on structural and optical properties of RF-sputtered $\mathrm{LiTaO}_{3}$ thin films, Mater. Res. Express, 6, 026405 , 2018.

[10] W. T. Hsu et al., Materials Optical Properties of $\mathrm{Mg}$, Fe, Co-Doped Near-Stoichiometric $\mathrm{LiTaO}_{3}$ Single Crystals, 5, 227-238, 2012.

[11] J. Wang, J. Gou, and W. Li, Preparation of room temperature terahertz detector with lithium tantalate crystal and thin film, AIP Advances, 4, 027106, 2014. [12] I. Bhaumik et al., Resonant Raman scattering in single crystal of congruent $\mathrm{LiTaO}_{3}$, Effect of excitation energy, Solid State Communications, 151, 1869-1872, 2011.

[13] C. R. Kalaiselvi et al., Solvothermal fusion of Ag- and $\mathrm{N}$-doped $\mathrm{LiTaO}_{3}$ perovskite nanospheres for improved photocatalytic hydrogen production, Applied Organometallic Chemistry, 35, 6, 2021.

[14] I. Sokólska et al., Spectroscopy of $\mathrm{LiTaO}_{3}: \mathrm{Tm} 3+$ crystals, Journal of Physics and Chemistry of Solids, 61, 1573-1581, 2000.

[15] A. Ismangil, Irzaman, and Irmansyah, The Diffusion Coefficient of Lithium Tantalite $\left(\mathrm{LiTaO}_{3}\right)$ with Temperature Variations on LAPAN-IPB Satellite Infra-red Sensor, Elsevier Enhanced Reader, 3, 1-5, 2016. 
[16] N. Djohan et al., The effect of annealing temperature variation on the optical properties test of $\mathrm{LiTaO}_{3}$ thin films based on Tauc Plot method for satellite technology, IOP Conf. Ser, Earth Environ. Sci., 54, 012093, 2017.

[17] A. Ismangil et al., The Effect of Electrical Conductivity of $\mathrm{LiTaO}_{3}$ Thin film to Temperature Variations, International Journal of Advanced Science and Technology, 29, 7, 2020.

[18] N. Djohan et al., The effect of indium oxide $\left(\mathrm{In} 2 \mathrm{O}_{3}\right)$ dopant on the electrical properties of $\mathrm{LiTaO}_{3}$ thin film-based sensor, Ferroelectrics, 568, 55-61, 2020.

[19] R. Estrada et al., The optical band gap of LiTaO3and Nb2O5-doped $\mathrm{LiTaO}_{3}$ thin films based on Tauc Plot method to be applied on satellite, IOP Conf. Ser Earth Environ. Sci, 54, 012092, 2020.

[20] I. Sh. Steinberg, A. V. Kirpichnikov, and V. V. Atuchin, Two-photon absorption in undoped $\mathrm{LiTaO} 3$ crystals," Optical Materials, 78, 253-258, 2018.

[21] I. Sh. Steinberg and V. V. Atuchin, Two-photon holographic recording in $\mathrm{LiTaO}_{3}: \mathrm{Fe}$ crystals with high intensity nanosecond pulses at $532 \mathrm{~nm}$, Materials Chemistry and Physics, 253, 122956, 2020.

[22] N. Sellami et al., Two-stage synergy of electronic energy loss with defects in $\mathrm{LiTaO} 3$ under ion irradiation, Materials Research Letters, 6, 339344, 2018.

[23] X. Yang et al., Up-conversion luminescence of LiTaO3:Er3+ phosphors for optical thermometry, Ceramics International, 46, 1178-1182, 2020.

[24] R. Hu et al., UV-Vis-NIR broadbandphotostimulated luminescence of $\mathrm{LiTaO}_{3}: \mathrm{Bi} 3+$ longpersistent phosphor and the optical storage properties, Chemical Engineering Journal, 392, 124807, 2020.

[25] A. J. Yencha, S. Y. Truong, and G. C. King, Threshold photoelectron spectrocopy of SO2 over the photon energy range 12-50 eV, Journal of Electron Spectroscopy and Related Phenomena, 233, 38-50, 2019.

[26] M. López-López, J. Vaz, and C. García-Ruiz, Confocal Raman spectrocopy for the analysis of nail polish evidence, Talanta, 138, 155-162, 2015.

[27] A. M. Dhumad, et al., Nonlinear optical properties investigation of a newly synthesised Azo$(\beta)$ - diketone dye, Journal of Photochemistry and Photobiology A: Chemistry, 418, 113429, 2021.

[28] J. Kaur, S. Rani, and B. Lal, Luminescence properties of Eu3+ doped gadolinium aluminum garnet phosphors, Optik, 212, 164745, 2020.

[29] T. Virtanen et al., Real-time fouling monitoring with Raman spectroscopy, Journal of Membrane Science, 525, 312-319, 2017.

[30] L. J. Fernández-Menéndez, et al., Spatiotemporal distribution of atomic and molecular excited species in Laser-Induced Breakdown Spectroscopy: Potential implications on the determination of halogens, Spectrochimica Acta Part B: Atomic Spectroscopy, 168, 105848, 2020.

[31] A.Ismangil, Irzaman, and Irmansyah, The diffusion coefficient of lithium tantalite $\left(\mathrm{LiTaO}_{3}\right)$ with temperature variations on LAPAN-IPB satellite infra-red sensor, Elsevier Enhanced Reader, 33, 668 -673, 2016. 